\title{
Perceptions of overweight African women about acceptable body size of women and children
}

Z. Mvo

$\&$

J. Dick

$\&$

K. Steyn

The South African Medical Research Council

\section{"It is caused by food. \\ 1 do not even want to lie. I like food very mesh"}

\section{ABSTRACT}

Purpose: Malnutrition, presenting as obesity in women and under-nutrition in children, is a prevalent problem in the squatter communities of Cape Town. Food habits are determined by a complex matrix of economic, social and cultural factors which need to be understood by health professionals prior to the implementation of strategies to improve the nutritional status of this community. This qualitative study is designed to explore the perceptions of overweight black women in Cape Town, with underweight infants, about the culturally acceptable body size for women and children.

Method: Qualitative in-depth interviews were conducted with 10 overweight black women who were resident in the metropolitan area of Khayelitsha in Cape Town. A snowballing technique was utilised to select the key informants, all of whom were mothers of underweight infants. The interviews were conducted in Xhosa and recorded, with the permission of participants, onto tape. They were then transcribed and translated into English. The transcripts were coded and analysed by two researchers who worked independently to ensure content validity.

Results: The informants came from disadvantaged communities in which food was highly valued as a result of the fact that food security was not assured. The concept of an individual voluntarily regulating the intake of nutrients when food did become available, appeared unacceptable to the informants. It was not clear from the interviews how the participants perceived their normal or "desired" body weight. Increased body mass was regarded as a token of well-being in that marital harmony was perceived to be reflected in increased body weight. Overweight children were regarded as reflecting health as it was associated with sufficient food supply and intake.

Conclusions: Although women expressed the desire to loose some excess weight for practical reasons, there was no negative social pressure to motivate this. The attitudes recorded from this qualitative research project suggest cultural perceptions of excess body weight that will complicate the design of effective health promotion strategies to normalise and maintain ideal body weight in this group of African women.

Keywords: Obesity, perception of body size, attitude and values, black women, Khayelitsha

\section{INTRODUCTION}

Health providers, whilst working amongst the lowest socio-economic groups in South Africa, are faced with a confusing anomaly; many mothers who present with undernourished infants and children at primary health care clinics are observed to be grossly overweight. Balanced nutrition is recognised to be the cornerstone of maintaining an optimum level of health, and efforts to improve the dietary habits of all members of the South African population remains a priority. Food security, patterns of food preparation and child rearing practices are determined by a complex matrix of social, economic and cultural variables. The observation that malnutrition in infants and over-nutrition in mothers coexist in the same family suggest that food scarcity or excess may not be the only factors involved. $\left({ }^{13,} 1\right)$

Health providers need a clear insight into 
the factors associated with under- and overnutrition prior to designing and implementing interventions to improve the health status of communities. Effective culturally sensitive nutrition programmes need to be based on an understanding of women's values concerning body size and perceptions of health. It is the aim of this study to explore some of these perceptions using a qualitative research method in the squatter community of Khayelisha, Cape Town.

Qualitative research attempts to understand the meaning and the behaviour from the perspective of the participant (10). In this approach the interpretation of the data emerges from an interaction between informants and researchers. The research becomes a recursive process of purposive sampling, collection, categorisation and interpretation of data (2).

\section{Under-nutrition in infants and children}

Malnutrition results from the inadequate intake of nutrients or from disease factors which affect the digestion and utilisation of nutrients. Infectious diseases have been shown to negatively affect both dietary intake and digestive processes ${ }^{(8)}$

Dietary intake depends on four factors: the meal frequency, the amount of food per meal, the energy and nutrient density of the food and the biological utilisation. Some studies ${ }^{(9.7)}$ have shown that protein-energy malnutrition, highly prevalent in developing countries, appears frequently during the infant's weaning period from 4 to 18 months of age. This is due to high energy breast milk being substituted by food which may be in scarce supply. In South Africa prolonged breastfeeding appears underutilised as a means of dealing with food scarcity. Under-nutrition in infants and children resulting in the stunting of the growth process, is closely associated with increased infant mortality, retarded mental development and an increased risk of developing infection ${ }^{(12)}$.

\section{Over-nutrition in black women}

Until the age of $14-15$ years at least $50 \%$ of black South African children are under the 3rd percentile of weight for age of the Boston reference standards ${ }^{(1)}$. The situation changes at adolescence, when approximately $50 \%$ of black females become obese, i.e. with a Body Mass In$\operatorname{dex}\left(\right.$ Weight $(\mathrm{Kg}) /$ Height $\left(\mathrm{m}^{2}\right)>30^{\text {(1). }}$. On the other hand, obesity amongst black males remains rare ${ }^{(8)}$, despite the fact that both sexes consume the usual high fibre, low animal fat and low protein diet with similar amounts of sugar consumption. Although it is suggested that black males are more physically active, experts regard physical activity as being only part of the explanation of the gender differentiation in body size amongst the South African black community.

International literature indicates a wide range of biological, psycho-social and cultural factors that contribute to the problem of obesity. While excessive caloric intake may lead to obesity, but may not be a factor in maintaining obesity once established $16,4,11)$. Although individual requirements for food energy, nu- ceptable body size for women and children.

\section{METHODS}

A qualitative study was implemented using in-depth interviewing techniques (2)to explore the cultural perceptions of body size of obese mothers with underweight children. The study was conducted in Khayelitsha, a large area of formal and informal housing in the metropolitan area of Cape Town.

A snowball technique of sampling was

\section{"And I could see that with the Depo injection am no longer having the body $/$ used to}

trients and psycho-social nurture do not vary significantly from one society to another, the resources to meet these needs may vary considerably. Overnutrition in adults is associated with the increased risk of developing non-communicable disease such as hypertension, diabetes, cardiac disease and certain types of carcinoma (3)

\section{Perceptions of body image}

Most studies on obesity and body image have been conducted in America. Stevens et al (11) explored the association between attitudes to eating with the perceptions of body size in obese elderly black and white women. The findings indicated that in the USA black women were more satisfied with their body size than white women. This suggests differences in cultural attitudes towards large body size. A similar study by Kemper ${ }^{(5)}$ showed significant differences between black and white adolescents perceptions of body size. In this project, adolescent females were requested to select from a wide range of illustrations "an ideal female body size" in order to explore the norms and expectations of family and friends. The black adolescents were more likely to select a larger body size than their white counterparts. They perceived that their parents considered them thin, while white adolescents thought their parents considered them "heavy". It became clear from this study that families and communities play a significant role in influencing standards of appropriate body size.

\section{Study aim}

To explore the perceptions of overweight black women in Cape Town, with underweight infants, about the culturally ac- utilised (2)to make contact with potential informants. The women were approached while attending the primary health care clinic in Khayelitsha. Redundancy of descriptions, a means of determining sample size in qualitative studies, occurred during the ninth and tenth interview. Sampling criteria were that the women be between the age of 18 and 45 years, black and Xhosa speaking, obese, and yet mothers of children described by the clinic nurses as underweight. All participants lived in a squatter community of Khayelitsha, which accommodates many black families recently migrating from rural areas to Cape Town in search of employment. Participants were approached by the researcher who requested their participation in the study. The researcher obtained informed consent from each participant and permission to record the interviews on audio-tape.

The interviews were held in the clinic setting while participants were waiting for a health provider consultation. The interview was routinely preceded by a culturally appropriate introduction of the researcher's cultural and professional background. All interviews were conducted in Xhosa which was the first language of both the participants and the researcher conducting the interviews. Probes specific to eliciting perceptions of body size and body size values of adults and children were elicited. Interviewing data concerning the participant's ideas of desired body weight, what was considered attractive and the relationship between health and body mass was also discussed. These probes included family and peer perceptions of weight gain or weight loss and the reasons for either gaining or losing weight. Food habits, food preparation and the 
choice of foodstuffs were also discussed The mean duration of each interview was 45 minutes.

The tapes were transcribed and then translated from Xhosa to English by the researcher and an assistant. The analysis of the content and techniques of constant comparison (2) were used to analyse the transcripts into categories, themes and contexts related to body size values and factors which influence those values. The reliability of the process of analysis was enhanced by having two colleagues review categories and context independently. The level of agreement using this process was very high. The results are reported as themes as is customary in qualitative research.

\section{RESULTS}

\section{Demographic data}

All the participants interviewed in the study had moved to Cape Town from the Eastern Cape region of South Africa; nine of the ten informants coming from the rural areas, whereas one came from the city of East London. The age range of the sample was from 18 to 36 years of age. All participants were mothers; most unmarried; and 9 out of the 10 participants unemployed. All participants lived in the shack communities of Makhaza, Site $B$ and Site $C$ in the suburb of Khayelitsha with households of 4 to 10 other occupants.

One of the participants had left school after 6 years of schooling, while the rest of the group had received 9 or 10 years of formal education. Due to the high unemployment rate in this group of participants, food security was problematic many of them relying on the generosity of their householders who supplied the food. Most of the respondents received no financial support from the fathers of their children.

\section{Under-nutrition in infants and children}

Most of the mothers described their babies as being "big at birth", but early in infancy the baby ceased to gain sufficient weight, "He is smaller now, he was fat before". This perception was reinforced by observations made by health providers at the primary health care clinics, "Even the nurses said that".

The mothers gave a variety of reasons as to why their infants failed to thrive. Many described the familiar cycle of ceasing to breastfeed as a result of seeking employment to supplement the famiIy's scarce resources, "She does not have proper food, nobody is working". The infant was then placed in the care of a childminder, who was not reliable: "My aunt is a drinking person"; "I discovered that she was not treating him well"; "She does not care about things". Some of the mothers described the child suffering from diarrhoea, followed from a period of hospitalisation.

The mothers described vegetables, eggs, cereal and milk as appropriate food for their children. "What I think would really make him gain his weight is spoon food". The main source of information regarding what to feed the child was the clinic nurse. The recurring problem was expressed as "Because they all (babies) stop breast feeding very early due to ill health. Then I have to feed them". The mothers usually made a type of porridge for the child's breakfast. The porridge may be accompanied with sour milk (amasi), soup or supplementary milk products such as SMA, Lactogen or Nestum. Some mothers supplemented bread flour for porridge. "I cook bread flour and pour it in his bottle". Other meals consisted of a mixture of cooked vegetables including rice and potatoes. A few mothers had problems feeding the child vegetables as the child did not like the food. "Really he does not like vegetables...you have to hold him and force him to eat".

Most mothers expressed a wish for the child to have a big body. One exception was a mother who associated plumpness with chest problems, "When the child is too big she is troubled by chest wheezing".

The mothers who reported getting food (milk) for her child from a Malnutrition Centre complained that the milk is limited to two tins every fortnight. They described the long wait, "You stay there from the morning till late". "You have to wake up at six as if you are going to work so that you can get the porridge to feed your child with". When asked if the children do get enough food from these centres, one mother replied, "Yes, they get enough food although you have to struggle to get that food. It is said that it is the place to feed children but you see people having up to three dishes in front of them. One is for herself, the other one is for the child, and the last one is for herself again". body I used to have...". Most of the women did not weigh themselves on a regular basis. They described themselves as fat because their clothes no longer fitted them, or because they heard other people comment about their large size.

Responses to the question on how the women felt about their body size varied. Some women felt that they were content with their shape as they associated being thin with times of stress and difficulty. "I think I experienced a lot of problems at my husband's home. Then I lost and lost weight". When asked if they were satisfied, they responded with replies such as, "Yes, I like it". They were content with their body size as they felt healthy and were not limited in their daily living activities. However, the majority of women expressed discontentment with their bodies, "I wish I could loose weight, and not be like this....."

The women who expressed their discontentment with their shape, gave three main reasons for their unhappiness. Firstly, they found that they were unable to wear clothes that they had previously enjoyed wearing, or that had been donated to them. Secondly, they expressed difficulty moving around, "No, it (the body) is heavy when you walk". Others felt uncomfortably hot during the summer days, "When it is hot I get a rash and I become very hot".

The attempts to loose weight were limited. One woman described that she drank lemon juice with black tea, while another described her attempts to restrict her eating habits. These attempts soon failed when she was placed in a situation with abundant food, "I sometimes try and not eat. My problem is that I can stay and not eat meat for some time, but when l eat it again, l eat it to make up for the times I was not eating it!"

The response of people close to the women varied considerably. Many family members and friends appeared to acknowledge the participants' large size without any negative feelings. "They say, "Wow, I wonder where do you get such a big body?" or "Yes, they do comment,

\section{"I wish I could loose weight, and not be like this ..."}

\section{Mothers' perceptions of their own body size}

All the mothers described themselves as "fat". Many blamed their large body size on the contraceptive injection, Depo Provera. "And I could see that with the Depo injection am no longer having the but they do not criticise. They just talk about the fact that I have gained.". Others described positive comments about their large size. "He (husband) praises me". A few women gave incidences when they had received negative comments about their largeness. "I work with coloured people, and they say l like food, that I am always eating, and that is why I 
am so fat".

Many of the women associated weight gain with the prescription of the injectable contraceptive Depo Provera. "No, its the Depo...... I became fat when I started using it". Others put on weight when they became worried and upset. This was sometimes associated with long periods of unemployment, "Not working forces you to eat because you are not doing anything". Others connected their obesity to excessive eating, "It is caused by food. I do not even want to lie. I like food very much". "I think maybe it is caused by eating too much". Sometimes the increased access to food was caused by happy circumstances such as getting a job or living with a generous relative.

\section{Discussion}

This qualitative research study was designed to explore the perceptions of "desired body size" of a group of obese black women with undernourished infants and toddlers. It forms an initial part of a bigger project that will be investigating the determinants of obesity in mothers and under-nutrition in children. The sample was obtained from women waiting for a consultation at the Khayelitsha primary health care clinic. This clinic serves a large residential area consisting of informal housing, and most of the women had recently translocated from the rural areas of the Eastern Cape. All but one of the mothers were unemployed and unmarried, and consequently had no source of secure income. The mothers told the familiar story of the inability to sustain breastfeeding, a problem which was related to a cycle of infection and the failure to thrive. Only one of the mothers was able to breastfeed for a period as long as three months. The reasons given for ceasing to feed the baby on the breast were often associated with the need to search for some means of employment. The infant was frequently put into the care of a childminder who was not conscientious in the care of the child. The main source of information regarding the feeding of the children was the clinic nurse, and in most circumstances the mother knew what she should be doing regarding the weaning of the infants. The children were often difficult to feed and it appeared obvious that these mothers needed the continual support which they obtained from professional health advisors. The encouragement of new mothers in initiating and maintaining breastfeeding in these informal settlements remains a priority. All the mothers desired their babies to be plump with the exception of one mother who associated a fat baby with chest problems.

Most of the women interviewed associ- ated their weight gain with the use of the contraceptive (Depo Provera) injection. A few could recognise the association of long periods of inactivity with overeating, especially when they were in situations where regular access to food was not assured. They communicated their association between food, pleasure and comfort. Thinness and loss of weight were associated with times of anxiety and problems.

The women interviewed did not weigh themselves routinely, and their perception of the body size was generated by comments from peers and the inability to fit into clothes that had been previously comfortable for them to wear. Although there had been recognition of their weight gain by their peers, this acknowledgement was not associated with any negative social connotations. In fact some participants had had positive feedback regarding their attractiveness from people significant in their lives. Negative comments quoted had come from members of another ethnic grouping.

The women who were unhappy about their obesity gave practical reasons for their dissatisfaction, such as feeling uncomfortably hot or heavy, or not being able to wear the clothes that others had given them. None of the women identified potential health reasons as a motivation to loose weight.

The descriptions participants gave to reduce their body mass, indicated that they had little knowledge of an effective strategy to achieve their aim. Their attempts to restrict their dietary intake were sporadic, and interspersed with periods of overeating. The use of black tea, without changing aspects of their diet, also indicated a poor understanding of the physiological basis of weight reduction. The mismatch between perceived causes of weight gain and the ways of losing weight is highlighted by this study. The focus on energy balance which current weight control programmes promote does not deal with the perceived causes of weight gain in this community. Although the transferability of results of this study are limited, there is an indication of the possible causes of the problems of obesity in women and undernutrition in children in this particular community. Factors associated with difficulties in maintaining prolonged breastfeeding in this under privileged community need to be explored further. The introduction of successful weaning practices in this type of community remains an important health priority.

\section{CONCLUSION}

These issues will be systematically investigated in a quantitative study designed to obtain a comprehensive overview of the issues associated with both under- nutrition and over-nutrition in this community. This descriptive research is perceived as an essential component of the process of developing effective health promotion programmes for similar communities. Effective health promotion interventions need to be based on a clear understanding of the cultural values concerning body size, patterns of food preparation and child rearing practices. 


\section{REFERENCES}

BADENHORST C., \& WALKER A.R.P. 1994. Obesity - How can women in developing countries cope? SA J Food Science Nutrition; 6(3): 83-84.

DENZIN N.K., \& LINCOLN Y.S. 1994. Handbook of qualitative research. Sage publications, London: New Dehli.

FLYNN M.A.T., \& GIBNEY M.J. 1991. Obesity and Health: Why slim? Prac Nutr Soc ., 50: 413-432.

JEFFERY R.W., \& FRENCH S.A. 1996. Socioeconomic status and weight c o ntrol practices among 20- to 45-year-old women. Am J Public Health,86(7):1005-1010.

KEMPER K., SARGENT R.G., DRANE J.W., VALOIS R.F., \& HUSSEY J.R. 1994. Black and white Females' Perceptions of Ideal Body Size and Social Norms. Obesity Research, 2: 117-126.

KUMANYIKA S., WILSON J., \& GUILFORD-DAVENPORT M. 1993. Weight-related attitudes and behaviours of black women.J Am Diet Assoc, 93:416-422.

MOCK N.B. 1994. Intra household correlations in maternal child nutritional status in rural Guinea: Implications for programme screening strategies. Bulletin of WHO, 72(1): 119-127.

O'KEEFE S.J.D., THUSI D., \& EPSTEIN S. 1983. The fat and the thin - a survey of nutritional status and disease patterns among urbanised black South Africans. $S$ Med J, 63(18): 679-683.

PELLETIER D.L. 1994. The relationship between child anthropometry and mortality in developing countries: Implications for policy, programs and future research. American Institute of Nutrition, $J$ of Nutrition, 1994; 124

POPE C., \& MAYS N. 1995. Reaching the parts that other methods cannot reach: an introduction to qualitative methods in health and health services research. $B M J$, 311: $42-45$.

STEVENS J., KUMANYIKA S.K., \& KEIL J.E. 1994. Attitudes toward body size and dieting: Differences between elderly black and white women. Am J Public Health, 84:1322-1325.

STEYN N.P. et al. 1995. Differences in nutritional status between caretakers of underweight and normal weight Pedi preschool children. S Afr J Food Sc Nutr, 7(2): 5359.

WALKER A.R.P., \& SEGAL I. 1980. The puzzle of obesity in the African Black female. (letter). Lancet, 1 (8162):263. 